vacuolated form characteristic of advanced embryos, whereas in the younger specimens the notochords had remained small and nonvacuolated. The development of the heart had been considerably disturbed, however, in the specimen grown for twenty days.

The Vipera embryos were all at an older stage when obtained. One specimen, which
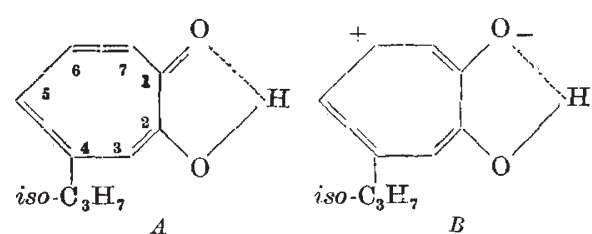

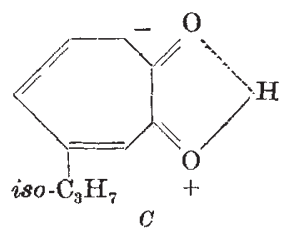
had a small allantoic bud, was cultured for four and a half days. During this time, the embryo lengthened and the allantois increased to about twice its original size and applied itself to the inner surface of the chorion.

The present experiments indicate that certain young embryos of British reptiles can survive and develop fairly normally in vitro for several days. It is suggested that by use of this technique a wide range of experimental work may become possible. Ruth Berlatrs

Department of Anatomy and Embryology, University College,

London, W.C.1. Dec. 17.

1 Pasteels, J., Arch. Biol, Paris, 48, 105 (1937).

${ }^{2}$ Waddington, C. H., Phil. Trans, Roy. Soc., B, 221, 179 (1932).

\title{
Benzalcoumaranones
}

THE discovery of the first benzalcoumaranone in Nature in the flowers of Coreopsis grandiflor ${ }^{1}$ has recently been followed by that of a second, aureusin, in Antirrhinum majus ${ }^{2}$. It would seem to be in the interest of biochemists and geneticists working in the field of plant pigmentation to introduce a less cumber. some term than 'benzalcoumaranone' for this class of pigments. In view of the golden-yellow colour which they impart or contribute to flowers in which they occur, and on the analogy of the term 'flavone' applied to the paler yellow pigments containing the pyrone ring, we suggest the term 'aurone' be employed in referring to the naturally occurring benzalcoumaranones.

E. C. Bate-Smith

Low Temperature Research Station, University of Cambridge, and

Department of Scientific and Industrial Research. T. A. GEISSMaN

Department of Chemistry, University of California,

Los Angeles 24, California. March 12.

1 Geissman, T. A., and Heaton, C. D., J. Amer. Chem. Soc., 65, 677 $(1943)$.

${ }^{2}$ Seikel, M. K., and Geissman, T. A., J. Amer. Chem. Soc., 72, 5725 (1950).

\section{Dipole Moments of Tropolone and Related Compounds}

ONE of us (T. N.) has carried out extensive studies ${ }^{1}$ on the chemical properties of hinokitiol (4-isopropylcycloheptatrien-2,4,6-ol-2-one-1) and assumed its structure to be the resonance hybrid among various electronic structures of the types, $A, B$ and $C^{2}$. $\mathrm{He}_{\mathrm{e}}$ also succerded in synthesizing this compound and its mother substance, tropolone.

We have measured the dipole moments of some of these compounds ${ }^{1,2}$ in berzene solution and have found the following values : tropolone (I, m.p. $51^{\circ}$ ), $3.71 \mathrm{D} .\left(25^{\circ}\right)$ and $3.64 \mathrm{D}$. $\left(35^{\circ}\right)$; tribromotropolone (II, m.p. $\left.126^{\circ}\right), \quad 1 \cdot 84 \quad D .\left(25^{\circ}\right)$; hinokitiol (III, m.p. $\left.52^{\circ}\right), 4.04 D .\left(33^{\circ}\right) ; \alpha$-monobromohinokitiol

(IV, m.p. $\left.56^{\circ}\right), 4 \cdot 32$ D. $\left(33^{\circ}\right) ; \alpha$-dibromohinokitiol (V, m.p. $\left.134^{\circ}\right), 4 \cdot 27$ D. $\left(33^{\circ}\right) ; \beta$-dibromohinokitiol (VI, m.p. $\left.96^{\circ}\right), 3 \cdot 14 \mathrm{D} .\left(20^{\circ}\right)$; $\alpha$-mononitrohinokitiol (VII, m.p. $\left.56^{\circ}\right), 6 \cdot 19$ D. $\left(25^{\circ}\right)$.

The dipole moments of I and III are much greater than can be accounted for by simple vector addition of bond moments using the valence bond structure of type $A$. They can be explained if we take into consideration the ionic structure of type $B$, with a formal positive charge at the ring-carbon atoms. This will give some degree of double-bond character to each bond in the ring, giving a plane cycloheptatriene ring. The direction of dipole moment in the molecule of III can be determined in the following manner. We assume that the moment of IV is the vector sum of that of III and the C-Br bond moment. It is highly probable from consideration of the course of its formation that the bromine atom is in position 7 . Hence the $\mathrm{C}-\mathrm{Br}$ moment is in the direction from the centre of the ring to carbon atom 7 . From simple geometry, using measured moments, it is concluded that the moment of hinokitiol is nearly in the direction from the centre of the ring to the middle point between two oxygen atoms. The moments of dibromohinokitiols and nitrohinokitiol can be calculated theoretically for various positions of substitution for comparison with the observed values. The conceivable position is at the carbon atoms 3,5 and 7 , as is evident from the molecular orbital treatment to be discussed later. Then the positions of substitution are 3, 5, 7 for II, 3, 7 for V, 5, 7 for VI and 7 or 3 for VIr.

We have carried out molecular orbital treatment similar to that by Wheland and $\mathrm{Mann}^{3}$ on methylenecycloheptatriene and tropolone, simplifying the problem as $\pi$-electron systems with due regard to the electronegativity of oxygen. We arrived at a reasonable moment with the positive end at the ring. The resonance energies of cycloheptatriene and tropolone were found to be $\mathbf{1} \cdot 994 \beta$ and $3.09 \beta$, respectively, as compared with $2 \beta$ for benzene. In the molecule of tropolone, $\pi$-electron distribution was found to be concentrated at carbon atoms 3,5 and 7 , which justifies our previous assumption that only carbon atoms 3,5 and 7 are attacked by electrophilic reagents.

Tetsuo Nozot
YukIo KURTA

Chemical Institute, Nagoya University, Nagoya.

Chemical Institute, Tohoku University, Sendai.

1 Nozoe, T., Science of Drugs, 3, $174(1949)$; other papers in the press. ${ }^{2}$ Nozoe, T., et al., Proc. Japan. Acad., 26, 38, 43, 47 (1950).

${ }^{3}$ Wheland, G. W., and M.ann, D. E., J. Chem. Phys., 17, 264 (1949).

[The following notes on related work by European and American workers will be of interest.--EDITORS.]

THE investigations of Erdtman and his collaborators $^{1}$ have shown that hinokitiol is identical with $\beta$-thujaplicin, which they isolated from the heart- 